\title{
Left Side Congenital Diaphragmatic Hernia with Sac and Broncho-Pulmonary Sequestration: A Report to Reinforce The Need to Excise the Hernia Sac
}

\author{
Parveen Kumar' ${ }^{1}$ Shasanka Shekhar Panda*2 and Yogesh Kumar Sarin ${ }^{2}$ \\ ${ }^{1}$ Department of Pediatric Surgery, Chacha Nehru Bal Chikitsalaya, India \\ ${ }^{2}$ Department of Pediatric Surgery, Maulana Azad Medical College, India
}

Received: 阱 June 27, 2018; Published: 制July 09, 2018

*Corresponding author: Shasanka Shekhar Panda, Department of Pediatric Surgery, Maulana Azad Medical College, New Delhi, 110002 , India

\section{Abstract}

A $1.2 \mathrm{~kg}$, preterm female baby presented with left sided congenital diaphragmatic hernia (CDH). On left subcostal exploration, left CDH with sac was identified. At the time of excision of sac, a large nodule was identified sequestered on sac, which was later identified as extrapulmonary sequestration of lung. The baby succumbed to persistent pulmonary hypertension and pulmonary hemorrhage in post-operative period.

Keywords: Bronchopulmonary Sequestration; Congenital Diaphragmatic Hernia; Hernia sac

\section{Introduction}

Congenital diaphragmatic hernia $(\mathrm{CDH})$ is a common congenital anomaly. The presence of hernia sac is less frequent. The bronchopulmonary sequestration (BPS) may be rarely associated with $\mathrm{CDH}$, may even be cited as a cause for same. The presence of BPS may interfere with proper closure of postero-lateral defect. It is prudent to excise hernia sac in order not to miss any associated BPS and avoiding risk of injury to same while repairing hernia defect (especially when plication of sac done).

\section{Case}

A two days old female baby, $1.2 \mathrm{~kg}$ birth weight, 35 week gestation, short for gestational age, referred to us with respiratory distress since birth. Baby had scaphoid abdomen. Chest X-ray showed bowel loops in left side of chest. Routine investigations were hemoglobin $15.7 \mathrm{gm} \%$, hematocrit $45.2 \%$, total leucocyte counts $9600 / \mathrm{cmm}$, platelets $80000 / \mathrm{cmm}$. Venous blood gas showed pH 7.41, pO2 68, pCO232mmHg, HCO3 15.4 and rest of investigations were within normal limits. Baby underwent left subcostal exploration and had left $\mathrm{CDH}$ containing bowel, stomach, spleen, left upper pole of kidney, left adrenal gland and a large hernia sac. Upper lip of diaphragm was well formed. Lower lip was not formed laterally. At the time of excision of sac, a large nodule was identified sequestered on sac(Figure 1). The hernia sac along with the nodule was excised and defect was repaired by non-absorbable proline sutures. In post-operative period, baby had deranged INR of 3.0, platelet count 82000 , urea 54, creatinine 2.1, $\mathrm{Na}^{+} 129, \mathrm{~K}+6.9$ and developed pulmonary hemorrhage and succumbed to persistent pulmonary hypertension. Histopathology of nodule revealed sequestered lung tissue.

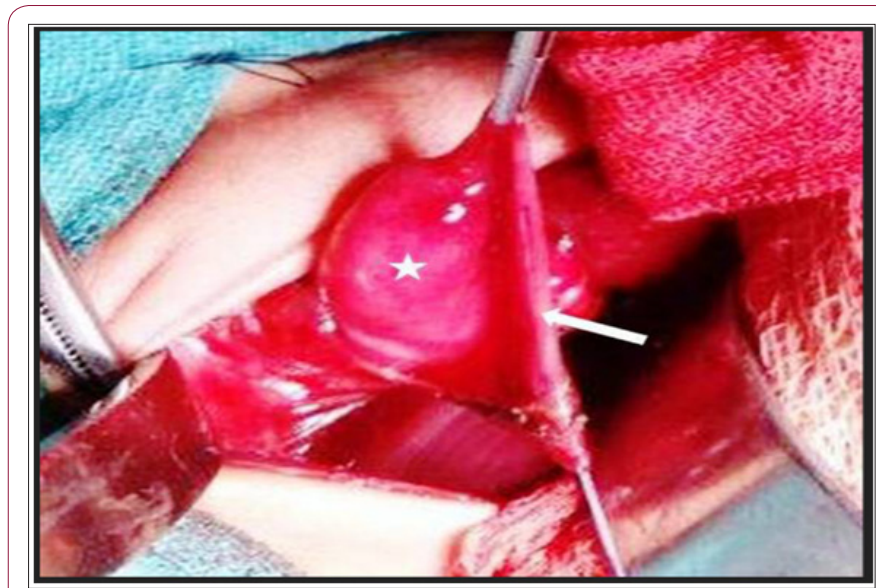

Figure 1: Intra-operative photograph showing a large nodule (white asterix) inside the hernia sac (white arrow).

\section{Discussion}

Congenital diaphragmatic hernia $(\mathrm{CDH})$ has an incidence of 1 in 2000 to 5000 live births. The embryology of diaphragm is complicated, with its origin from 4 sources; septum transversum, dorsal mesentry, pleuro-peritoneal membrane and muscular component. Failure of fusion of various components results in various types of CDHs. The Bochdalek hernia, most common type, results in posterior-lateral defect due to non-fusion of pleuroperitoneal membrane and septum transversum. Kluth et al. in experimental rat model, showed failure of normal growth of the post-hepatic mesenchymal plate (PHMP), resulting in CDH[1]. $\mathrm{CDH}$ has associated congenital anomalies in $30-40 \%$ cases.These 
may include cardiac, urinary tract, gastrointestinal tract, central nervous system defects, skeletal and neural tube defects.

Broncho-pulmonary sequestration (BPS) is defined as nonfunctional lung tissue that has lost communication with normal developing lung during embryonic development.It usually has an anomalous systemic blood supply. BPS comprise approximately $6 \%$ of all congenital malformations, and these are associated with $\mathrm{CDH}$ in $30-40 \%$ of cases[2].Interlobar sequestrations are far more common but Chadha et al found that extralobar type is more common when associated with other congenital anomalies[3].BPS presence at the site of future diaphragm may hamper its proper development and may infact be the cause of $\mathrm{CDH}$. The hernia sac is present in around $20 \%$ of $\mathrm{CDH}$ patients. It is formed by parietal pleura and peritoneum. The prognostic value of a hernia sac was studied by Grizelj et al. showed that hospital survival was significantly higher for those with hernia sac[2]. Spaggiari et al. postulated in their study that the presence of a hernia sac is associated with a higher pulmonary volume and a better overall prognosis for $\mathrm{CDH}$ [4]. Panda et al. reported a significantly lower mortality in isolated CDHs with a hernia sac[5].

The beneficial effect of sac may be attributed to lesser herniation of abdominal contents to lung cavity and thereby lesser lung compromise and hypoplasia. The $\mathrm{CDH}$ overall has a high mortality rate of 30-50\%[6].The pulmonary hypertension and hypoplasia are the leading causes of postnatal morbidity and mortality. Our case succumbed due to persistent pulmonary hypertension.

ISSN: 2574-1241

DOI: 10.26717/BJSTR.2018.06.001367

Shasanka Shekhar Panda. Biomed J Sci \& Tech Res

(C) This work is licensed under Creative

Submission Link: https://biomedres.us/submit-manuscript.php

\section{Conclusion}

We report this case to postulate that the presence of BPS may be a cause for $\mathrm{CDH}$ and to reinforce the need of excision of hernia sac, to aid in complete excision of BPS and prevent its intra-operative injury and future diagnostic dilemma.

\section{References}

1. Kluth D, Keijzer R, Hertl M, Tibboel D (1996) Embryology of congenital diaphragmatic hernia. Semin Pediatr Surg 5(4): 224-233.

2. Grizelj R, Bojanić K, Vuković J, Novak M, Weingarten TN, et al. (2017) Hernia sac presence portends better survivability of isolated congenital diaphragmatic hernia with "liver-Up". Am j Perinatal 34(5): 515-519.

3. Chadha R, SinghD, Kathuria P, Sharma S, Choudhury SR, et al. (2006) Congenital cystic adenomatoid malformation associated with ipsilateral eventration of the diaphragm. Indian J Pediatr 73 (9): 832834.

4. Spaggiari E, Stirnemann J, Bernard JP, De Saint Blanquat L, Beaudoin S, et al. (2013) Prognostic value of a hernia sac in congenital diaphragmatic hernia. Ultrasound Obstet Gynecol 41: 286-290.

5. Panda SS, Bajpai M, Srinivas M (2013) Presence of hernia sac in prediction of postoperative outcome in congenital diaphragmatic hernia. Indian pediatr 50 (11): 1041-1043.

6. Brownlee EM, Howatson AG, Davis CF, Sabharwal AJ (2009) The hidden mortality of congenital diaphragmatic herniaa 20-year review. J Pediatr Surg 44 (2): 317-320.

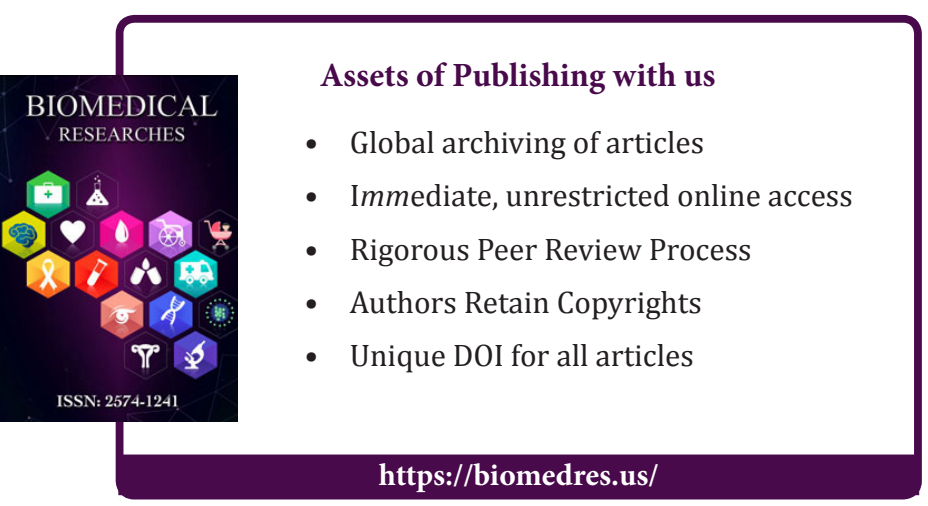

Cite this article: Parveen K, Shasanka SP, Yogesh KS. Left Side Congenital Diaphragmatic Hernia with Sac and Broncho-Pulmonary Sequestration: A Report to Re-In force The Need to Excise the Hernia Sac. Biomed J Sci\&Tech Res 6(3)- 2018. BJSTR. MS.ID.001367. 